\title{
The Use of Organisational Learning Practices in Start-Ups Growth
}

\author{
Viktorija Baltrunaite, Jurgita Sekliuckiene
}

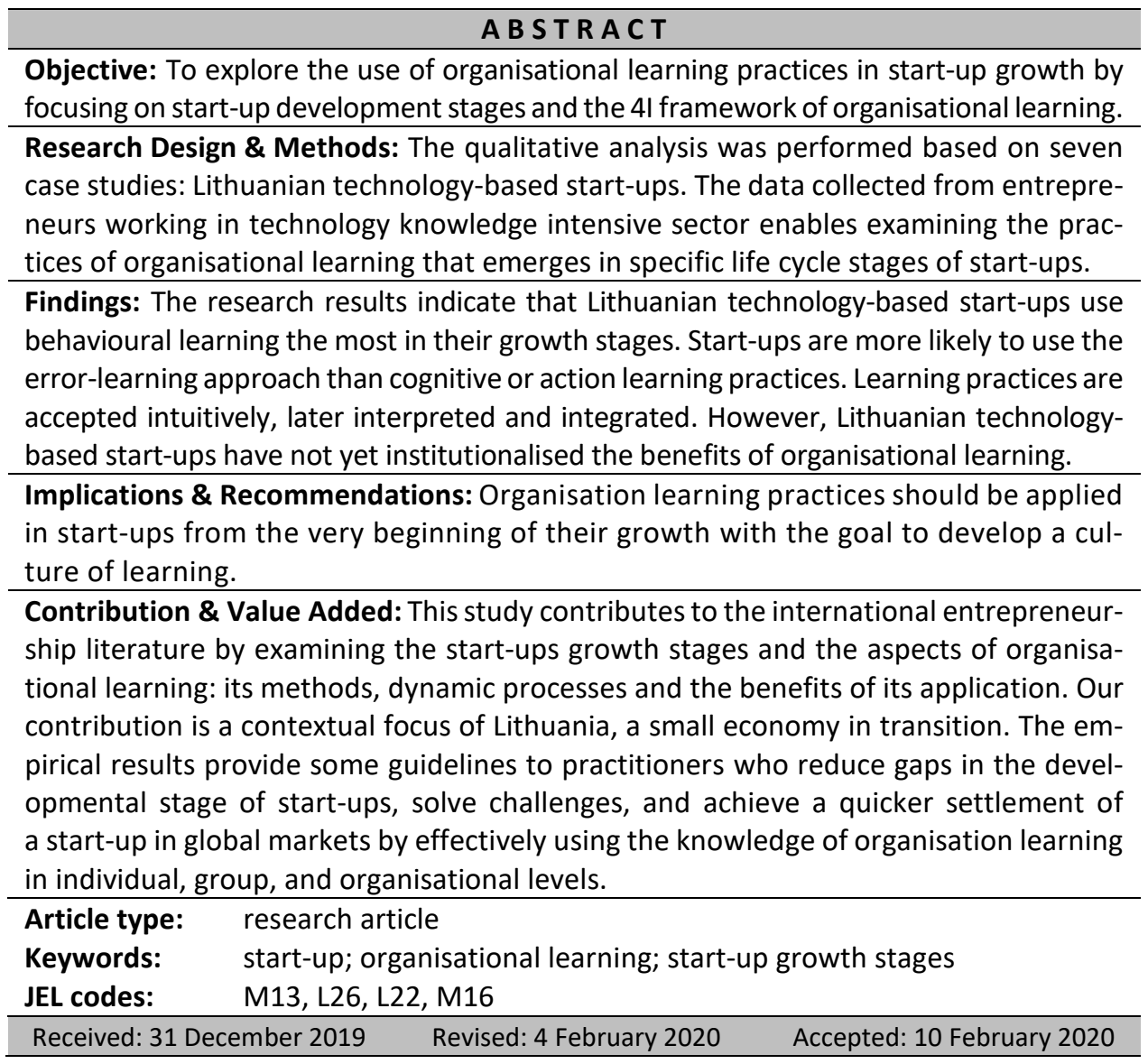

\section{Suggested citation:}

Baltrunaite, V., \& Sekliuckiene, J. (2020). The Use of Organisational Learning Practices in Start-Ups Growth. Entrepreneurial Business and Economics Review, 8(1), 71-89. https://doi.org/10.15678/EBER.2020.080104 


\section{INTRODUCTION}

The globalisation of countries, the openness of markets, and the development of technologies made a positive stimulus for new business creation: start-ups. Due to the large number of start-ups and various new management mechanisms, structures and actions emerging from these business activities in markets, research on start-ups, along with the growth and internationalisation of start-ups receive increasing attention especially in the past decade (Blank \& Dorf, 2012; Bosch, Olsson, Björk, \& Ljungblad, 2013; Chung \& Bowie, 2017; Pomerol, 2018; Swanson \& Baird, 2003). However, researchers show that more than half of all startups fail most often without reaching their fifth year of activity and they do not perform any international activity (Henry, 2017; Swanson \& Baird, 2003; Sweetwood, 2018).

Many authors analyse challenges that arise from start-up activities, which sometimes leads to their collapse (Cantamessa, Gatteschi, Perboli, \& Rosano, 2018; Mueller, Volery, \& von Siemens, 2012; Wang, Edison, Bajwa, Giardino, \& Abrahamsson, 2016), while frequent research emphasises the importance of organisational learning for start-up competitiveness, inter-knowledge sharing, and operational efficiency (Brockman, 2013; Chandler \& Lyon, 2009; Chen, Lin, \& Yen, 2014; Lumpkin \& Lichtenstein, 2005; Tam \& Gray, 2016). Although there is a high variety of frameworks in organisational learning $(\mathrm{OL})$, previous entrepreneurial research applied $4 \mathrm{I}$ OL framework provided by Crossan, Lane, and White (1999). The 4I OL framework includes the environments of an individual, a group, and organisational learning. Organisational learning process among all team members in different start-up development phases and international growth is one of the most important source of innovation (Sekliuckiene, Vaitkiene, \& Vainauskiene, 2018). Group knowledge in start-up teams contributes to the success of the start-up, and team engagement in knowledge-acquisition activities has a major impact on high start-up results (Chandler \& Lyon, 2009).

However, there is a lack of research that would reveal interactions at every stage of startup development, when organisational learning practices are used, which may show how organisational learning differs at each stage of the start-up life cycle. Thus, individual, entrepreneur, and organisational learning are important aspects that affect the growth of firms (Koryak, Mole, Lockett, Hayton, Ucbasaran, \& Hodgkinson, 2015). Despite the fact that there exist some research issues in this area (Baggen, Lans, Biemans, Kampen, \& Mulder, 2016), most scientific works are devoted to the entrepreneurial individual (Cosenz \& Noto, 2018), although organisational learning can be viewed from the perspective of the continuous learning process. Thus, in this article, we address the gap in the literature by drawing upon organisational learning and entrepreneurship theories so as to analyse technology-based start-ups' ability to apply organisational learning practices in entrepreneurial business growth.

This article poses the following research question: how do start-ups apply organisational learning practices in entrepreneurial business growth? In order to examine this matter, we performed an in-depth qualitative analysis for the case study on the example of seven technology-based Lithuanian start-ups.

The paper contributes to the existing literature in two ways. Firstly, the research develops the theory of entrepreneurship by showing the importance of organisational learning practices in start-up development. Secondly, the article shows the specific context of Lithuania, a Baltic country in transition, for technology-based start-ups growth. 
The text is organised as follows. First, theoretical background is provided. The second section explains the methodology used to explore Lithuanian technology-based start-ups. The third section presents the main results of the empirical study. The final section integrates conclusions of the study and is followed by discussion and future research directions.

\section{LITERATURE REVIEW}

\section{Start-Ups Characteristics}

Start-up is a small company most often with a high-tech focus (Swanson \& Baird, 2003), which proposes a new product or service to the market in conditions of extreme uncertainty (Bosch et al., 2013) while aspiring to grow fast (Wang et al., 2016). Most often, startups have limited resources in terms of people and funding (Bosch et al., 2013), which leads them to struggle for existence (Salamzadeh \& Kesim, 2015). These entities are mostly formed based on new ideas that increase instability in economy by putting all business under the pressure of innovation and disruption (Pomerol, 2018). Many start-ups are going global by engaging in international activities (Bürgel, Fier, Licht, \& Murray, 2004) and making the expansion processes as the core of their interests (Bailetti, 2012).

The main role in recognizing, evaluating, and exploiting the opportunities during the growth of a start-up lies with the entrepreneur (Mueller, Volery, \& von Siemens, 2012) whose first steps depends on the entrepreneur's ability to decide how and where to use available resources (Alvarez \& Busenitz, 2001). According to Aldrich and Yang (2012), the founder of a start-up performs actions oriented towards a goal according to the logic of a tripartite action: routines, habits, and heuristics. Each entrepreneur has four types of capital that he uses to create a start-up and achieve his or her goals (Karataş-Özkan, 2011): 1) economic capital that represents the amount of financial resources that it has or may have access to; 2) business know-how; 3) social capital that is the entrepreneur's connections gathered by knowing and maintaining partnership with universities, work environments, or other networks; and 4) symbolic capital that combines the three types of capital categories mentioned above with the help of personal qualities such as power and independence. A new business founder must have appropriate resources, such as education, experience, strong relationships, personal savings, and financial contributions from a close environment to start a new venture and turn his capital into start-up capital (Lichtenstein \& Brush, 2001).

According to Osnabrugge and Robinson (2000), there are three types of start-ups which have great potential to grow: lifestyle ventures, middle-market and high-potential start-ups. Lifestyle ventures are based on an activity that provides sufficient capital to the founders of the company, but they are not inclined to high growth as this increases potential risk. Companies of this type mostly use internal funding, because their lack of propensity to expand has little chance of attracting funding from external sources (Osnabrugge \& Robinson, 2000). Meanwhile, middle-market high-potential start-ups are already considered to be business enterprises prone to rapid growth. Middle-market companies have an annual growth probability of more than $20 \%$ and more than 10 million USD revenue over a five-year period. This type of start-ups has the ability to attract external investors, mostly business angels, but also to finance its growth processes by bootstrapping. High-potential firms have a growth rate of over $50 \%$ a year, with a fiveyear projected return of more than 50 million USD, and 50 or more employees in a 5- 
10-year period. These are companies able to quickly adapt and change as needed - to take risky decisions - and their growth rates are attractive to both business angels and venture capitalists. Start-up financing method depends on its type (Jones, Macpherson, \& Jayawarna, 2014). Thus, the availability of start-ups to certain funding sources directly depends on their stage of development and type of business.

Funding at the start-up seed stage is considered to be the riskiest, because investors do not receive any income; no business or financial plan is available (Paschen, 2017). As a result, most costs associated with start-ups early-development phase are usually financed from the personal resources of entrepreneurs, from their family and friends (MaRS, 2009a), from donation crowdfunding (Paschen, 2017), or bootstrapping resources (overdrafts, credit cards). These investors are the most attractive in the first start-up phase because start-ups do not have to offer a tangible potential reward, and their investment is minimal (Paschen, 2017). In case a start-up fails, investors will suffer lower losses. At the start-up stage, the investment risk is reduced because the start-up product concept stage was achieved. Moreover, since a business plan is already prepared, there are clear financial needs. A start-up at this stage usually attracts investment from business angels, as this stage is the most attractive and they fund the start-up individually or by assembling a group of investors (MaRS, 2009b). Moreover, at this stage, there remains the importance of funds from the close circle of the entrepreneur, because these can form guarantees for borrowing from the bank (Jones et al., 2014). Investment risk at the early stage significantly decreases compared to the first two stages, because the new venture demonstrates business traction. At this stage, business angels and venture capital investments are the main financial sources (MaRS, 2009c). Even if a start-up was funded by banks in the previous stages, early stage intensifies the lending (Jones et al., 2014), money borrowed from banks are used more for everyday start-up operations. At the last stage, investments for further development come from VC funds, institutional investors, and venture leasing companies. At this stage, the risk is reduced due to the already established relationship with customers and suppliers and revenue scaling. However, market competition remains, so minimum start-up risk remains (MaRS, 2009d).

There are three categories of actions that entrepreneurs take in their start-up development: activities, functions, and features (Mueller et al., 2012). Exploration and exploitation of opportunities become very important at each start-up action. Activities are mainly management tasks for exchanging information, analytical and conceptual work, contact support and networking, and constant start-up monitoring. Functions are actions organised according to organisational context. Features include start-up management, marketing, sales, product/service and organisational development, human resources, financial control, and ongoing environmental monitoring. Actions related to possibilities exploration, identification, research, and obliteration are exploration startup activities. Meanwhile, exploitation encompasses the implementation and execution of opportunities discovered in start-up activities.

Countries encourage the emergence of start-ups by creating various funding (loans and grants) and mentoring programs, or by establishing support mechanisms such as incubators and hatcheries (Jones et al., 2014). The authorities try to raise awareness of the importance of start-ups in society. Salamzadeh and Kesim (2017) distinguish six different support mechanisms that contribute to the development of start-ups at various growth 
stages: incubators, accelerators, hatcheries, small business development centres (SBDC), angel investors, and science parks. Accelerators and hatcheries engage in start-up activities through intensive mentoring programs. Moreover, accelerators offer a variety of workshops for start-up learning, incubators train start-ups to work with human resources and advise on legal issues, while hatcheries mainly work with start-up introduction to the market. Incubator and accelerator support mechanisms are named as the most common contributors to start-up activities (Motoyama \& Knowlton, 2017).

\section{Start-Up Growth Stages}

Although researchers distinguish a different number of start-up development stages, the features are relatively similar in character. Osnabrugge and Robinson's (2000) framework distinguishes four start-up development stages. 1) Seed stage is a stage when only the idea of a potential new venture undergoes elaboration. A new venture creator expects to have a potentially profitable business idea, but it needs to be analysed, developed, and validated. 2) Start-up stage is when a new venture already started, progressing from an already approved idea to work with product development and a marketing campaign. Most often, the new venture at this stage is still small. 3) Early stage is a development phase when the new venture is expanding, the product or service is in production and marketing. In most cases, this phase takes less than five years and may still be unprofitable. 4) Later (expansion) stage is the maturity stage of the company. A venture is established, most likely profitable and with predictable cash flows.

Tech (2014) distinguishes three different stages of start-ups: 1) early, 2) growth, and 3) later. Each stage is described through the organisation, product, market, and funding prisms by presenting young venture activities specific to each stage.

Three stages breakdown are made by Paschen (2017), who distinguishes 1) the prestart-up stage when the founder of a new venture verifies the ability of his idea to become a real business by dealing with significant client problems. At this stage, main competitors, partners and suppliers are identified by working with the target market. 2) The second stage is the start-up stage when the business idea and the reliability of the business model are already proven. At that stage, the entrepreneur seeks possible improvements to the product prototype and creates a viable business plan. 3) Third stage of start-up is called the growth stage when a start-up becomes productive and profitable. It now conducts market penetration and scaling operations as the product is already approved on the market, so that the start-up has the potential to grow steadily.

According to Salamzadeh and Kesim (2015), a start-up's development may also be divided into three stages. 1) In the first, bootstrapping stage, the entrepreneur seeks to create a profitable venture by initiating various activities to implement his idea. At this stage, the first close environmental investment is obtained, but the risk of uncertainty is high. The bootstrapping stage needs to reveal the biggest advantages of product, team, financial management and customer interest in the product. 2) The seed stage is characterised by a high level of uncertainty, but the main aspects of this stage are the creation of a product prototype, entry into the market, and the search for additional assistance from support mechanisms (incubators, accelerators, investments). This stage also includes start-up evaluation. As a result, this stage is important due to the large number of start-ups failure in finding support mechanisms. However, start-ups that outlast this stage have great opportunities to become 
profitable companies. 3) The latest, creation stage, is the stage of product sales, market entry, and first employee recruitment. The company is formed at the end of this stage but still seeks additional sources of funding. Finally, a company becomes mature and profitable and looks for opportunities of development, diversification, and internationalisation.

\section{Organisational Learning and Its Dynamics}

Organisational learning promotes cooperation, allocation, and integration processes among team members; it creates innovative environment in the company and increases competitive advantage, should individual employees' practice and share learning at work and should a firm support a learning-conducive workplace in the long run (Chen et al., 2014; Tam \& Gray, 2016). Organisational learning helps to expand a business to new arenas by creating new knowledge, building new understandings, and detecting and correcting misalignments (Lumpkin \& Lichtenstein, 2005). A start-up must ensure development processes through action and advanced cognitive learning in different size of groups because organisational learning involves whole organisations into the learning processes; although still most of the learning happens at an individual level (Chandler \& Lyon, 2009).

Firms that promote and use organisational learning in their activities have an increased likelihood of recognising various market opportunities and adapting them to their business or to the process of establishing other companies (Lumpkin \& Lichtenstein, 2005). Three different methods of organisational learning can be used in company activities. According to Osnabrugge and Robinson (2000), there are three types of start-ups which have great potential to grow: lifestyle ventures, middle-market and high-potential start-ups. It is based on the reactions of one's organisation or other organisations to the various company routines, systems, structures, and technologies that occur when there exist inefficient processes or gaps in the market. Cognitive learning explores how individuals' cognitive maps affect the entire organisation's cognitive schema. Cognitive learning specifically focuses on learning processes rather than on behavioural outcomes. If members of an organisation effectively utilise this type of learning, basic data can become a knowledge base generated by the organisation as a whole or by certain organisational competencies that can provide a significant competitive advantage in the market. Action learning helps to achieve the best possible action at a given moment; it analyses the gap between a person's claim that he will perform a certain action and the actual action. If a group of people working in an organisation uses action learning methodology, a community of learning practice is often created that can significantly increase the company's performance in areas such as intercommunication, innovation, and team efficiency.

The debate on firm organisational learning was initiated by Jones and Macpherson (2006) who undertook the development of the 4 I model, designed by Crossan et al. (1999). The 4 I framework is highly applicable in the investigations on SMEs learning, from individual through group to organisational levels of learning (Jones \& Macpherson, 2006). The 4 I framework of organisational learning by Crossan et al. (1999) contains four related processes:

1. Intuiting is one person's intuitive behaviour based on his or own experience, a person's behavioural model.

2. Interpreting is an understanding of actions by individuals. In this process, it is important to understand the verbal and non-verbal communication of an obsessive person. 
3. Integrating is the process of generating a common and equally acceptable understanding of people in a group and, at the same time, adjusting coordinated actions. This process is primarily informal but - through dialogue and the integration of joint action - it can be institutionalised to become meaningful.

4. Institutionalising is a process that seeks to ensure the emergence of routine actions in an organisation and creates collective knowledge formalised within an organisation. This is done through clearly defined actions, tasks, and organisational mechanisms.

The 4 I organisational framework works when an individual - through previous experience and intuition - finds a business opportunity to explore through individual action models (Dutta \& Crossan, 2005). Then, the individual shares own insights with a larger group of people who join the process to interpret and explore the emerging business opportunity so as to create a common business proposition. Later, this common understanding becomes enabled commonly across the organisation through created systems, procedures, and overall strategies.

\section{The Use of Organisational Learning Practices in Start-Up Development Stages}

We combined the process of organisational learning with three start-up stages into the development model created by Brockman (2013) to evaluate the evolution of this process during the growth of a start-up (see Figure 1). Start-up development begins with the intuitive process: we first and foremost recognise the opportunity at the individual level. Since in this start-up stage its activity is only being prepared, there is an incubation period, so that everything depends on the entrepreneur's ability to learn at this stage, recognise the potential of the external environment, and exploit it by adapting own internal abilities. Soetanto (2017) summarises this approach by emphasising that the entrepreneur is "learning-by-doing" while analysing erroneous activities, working on problem-solving, and discovering solutions. This is tantamount to entrepreneurial alertness, the ability to detect opportunities, the added value of the product in development, and the ability to adapt and implement it all. As Ghezzi (2019) declares, it is the act of discovery and pursuit of profitable opportunities that builds the start-up in this phase. The engagement in seeking opportunities and advantages. At this start-up phase, action learning is important, which comes from the founder's responses to emerging market relationships and own knowledge and experience.

In the start-up phase, one person's intuition during connections with others (stakeholders, entrepreneurs) becomes an interpretation, and the start-up begins to assume a certain shape. Participation in different communities, networks is important learning source that promote the transfer of skills and existing knowledge within the team members (Soetanto, 2017). Thus, group connections may become a common understanding that arises from the interpretation of a single individual to the overall integrating process of the entire organisation. At this stage, behavioural learning is particularly relevant to action learning, group beliefs, and interpersonal relationships. However, the identification and exploitation of opportunities at this stage are still more informal and have not yet reached the institutionalising process.

In start-up growth phase, including international growth, learning is transferred from an individual to a small group until the entire organisation thinks its processes and structures through. If organisational learning reaches an integrating process in this start-up 
phase, learning in growth stage becomes the institutionalising process. Due to common and combined mental model, the process of learning becomes a dynamic activity for the whole start-up. All three learning modes are used here: cognitive, behavioural, and action. Depending on the company's activities and processes, their importance is constantly changing, thus creating an ideal learning environment. When start-ups become connected, learning makes it easier to innovate and divide available capabilities, because information is used in a collective knowledge system.

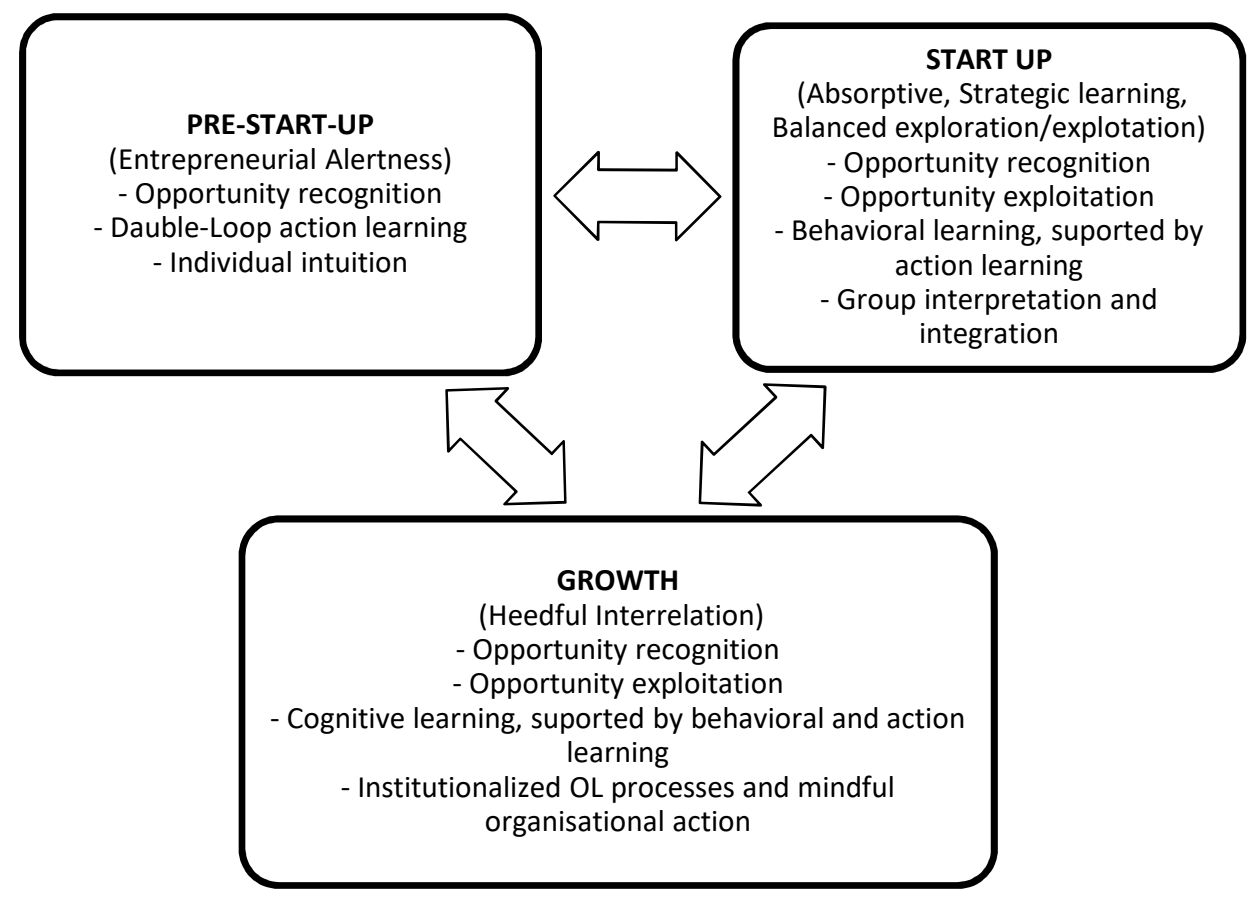

Figure 1. Organisational learning in start-up development Source: own elaboration based on the Brockman model (2013).

Seeking to integrate possible organisational learning solutions that could potentially improve start-up activities, we developed the framework below (see Figure 2).

It can be stated that a purposefully implemented organisational learning process can increase the competitive advantage in market due to the promotion of cooperation and discussion inside a start-up. This helps to ensure different learning and the creation of a collective knowledge-based system. Similarly, the use of organisational learning practices in start-ups ensures continuous market monitoring, learning from other startup experiences, integrated response to specific situations, and the implementation of a common strategy for the understanding of start-up information and knowledge for each team member. 


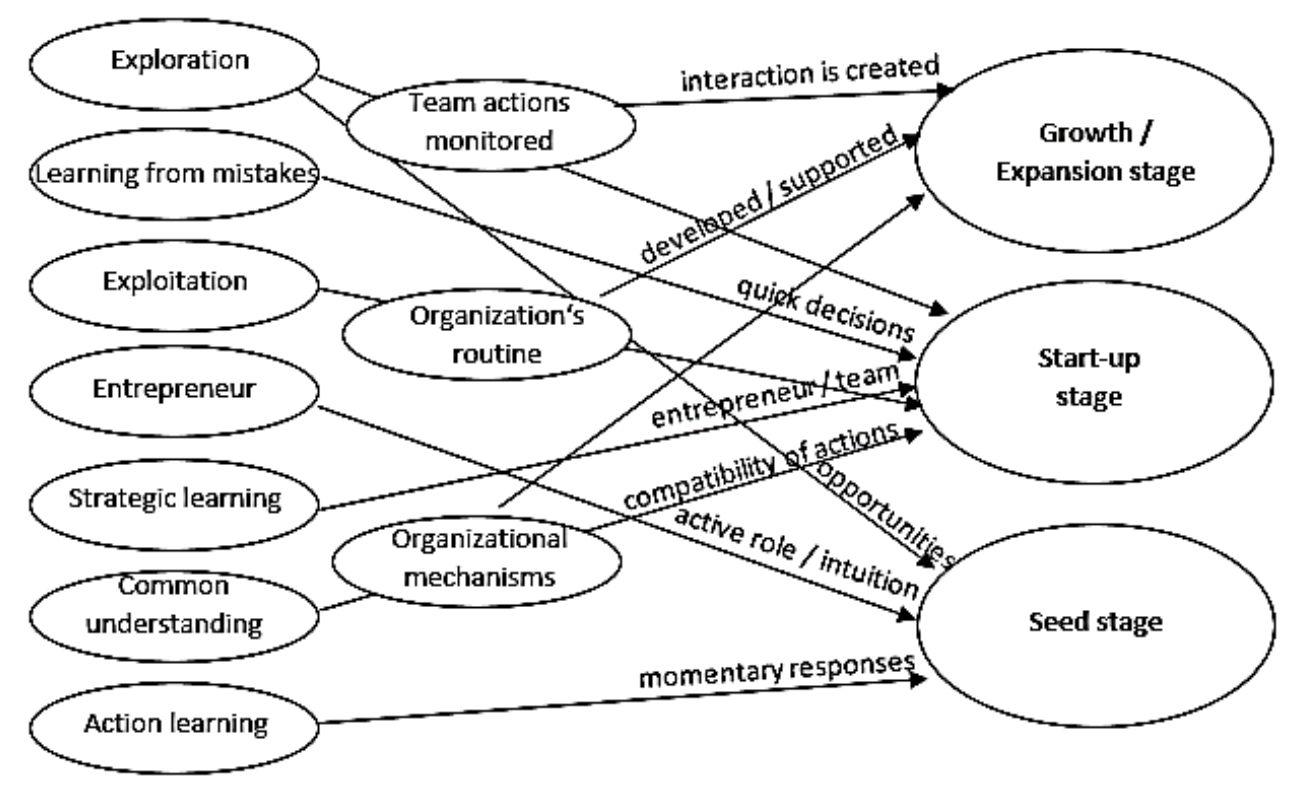

Figure 2. Framework of organisational learning practices in start-up growth Source: own elaboration.

\section{MATERIAL AND METHODS}

\section{Research Design}

\section{Research Method}

The objective of this study is to define how start-ups apply organisational learning practices in business growth. Based on this perspective, we used a descriptive case study design in this research to describe the phenomenon and real-life context in which this application occurs (Yin, 2003), while gathering data with several different methods: especially observation and interviews (Eisenhardt, 1989). The research is based on a qualitative approach that sought to describe and define the social construction of reality: to understand how a particular theory works in real investigated examples (Eisenhardt \& Graebner, 2007) and also to be able to enhance the development of quality measures and find the way to improve quality efforts in the analysed cases (Sofaer, 2002). Findings from the qualitative research stimulate practitioners' interest by allowing them to compare own daily practices with research findings and create new practices in their work (Silverman, 2016).

Qualitative research was conducted with a method of individual in-depth interviews. During these interviews, we analysed pre-defined topics and issues. When needed, these interviews were adapted to the specific context of the organisation under investigation by supplementing the questionnaire with unforeseen elements or changing questions depending on the situation.

All the interviews were conducted face-to-face. Each interview lasted from one to three hours. Audio-recording technology was used during the interviews to collect data and process it to transcripts. All interviews have been fully transcribed. 
The data gathered during individual interviews has been processed and systemised according to interview transcripts, later analysed and divided into subcategories connecting the OL method with OL processes: behavioural learning / interpreting, behavioural learning / integrating, cognitive learning / intuiting, cognitive learning / interpreting, cognitive learning / integrating, action learning / interpreting, action learning / integrating. This allowed us to later connect each growth stage with $\mathrm{OL}$ methods and processes and provide conclusions based on the connections.

\section{Sampling}

The case studies comprised seven Lithuanian start-ups that represent information communications technology (ICT) and technology fields. The firms selected for the research had to meet the following criteria: 1) the firm is categorised as small or medium-sized; 2) the firm's activities should be technology-based; 3 ) the firm should be founded in Lithuania. Founders of the firms or CEOs were interviewed, which allowed us to gather answers from seven informants. The CEOs an in-depth knowledge of their start-ups' growth and organisational learning practices.

Because of contextual focus, the Lithuanian context was important in this research. According to InvestLithuania (2019) and StartupLithuania (2019):

- Lithuania has a population of young professionals who have $85 \%$ proficiency in English, they are third in CEE for Bachelors graduates in science, maths, computing, engineering, manufacturing, and construction, and Lithuania has the third highest share of youth (25-34 years old) in tertiary education in the EU (55.2\%). Moreover, Lithuania is first in CEE for university-business collaboration in research and development.

- Lithuania is 11th globally for the ease of doing business; it takes one day to register a business using e-signature; and Lithuania is among the top ten EU countries in digital public services for businesses.

- Lithuania has growth-friendly taxation levels; third lowest corporate profit tax in CEE and $0 \%$ tax on profits in Free Economic Zones.

- Lithuania is ranked first globally for fulfilling business needs for ICT in areas like 4G availability (ninth globally), public Wi-Fi speed (first globally), and National Cyber Security Index (first globally).

- Lithuanian government and other institutions provide various support mechanism for start-ups, such as governmental support, pre-accelerators, accelerators, investments, incubators, hubs, sandboxes, and other support programs.

These specific features of Lithuanian start-up ecosystem provide a positive stimulus for technology-based start-ups creation in Lithuania. Table 1 below offers a description of sample start-ups.

The analysed start-ups operate from one to ten years and have teams counting from three to 18 people. The interviews occurred from the end of October 2018 until the be-ginning of December 2018. 
Table 1. Description of the case studies

\begin{tabular}{|c|c|c|c|c|c|}
\hline Activity & Industry & $\begin{array}{l}\text { Year of founda- } \\
\text { tion/Age of the } \\
\text { start-up }\end{array}$ & $\begin{array}{l}\text { Number of } \\
\text { founders }\end{array}$ & $\begin{array}{l}\text { Number of em- } \\
\text { ployees }\end{array}$ & Technology \\
\hline Start-up A & \begin{tabular}{|c|}
$\begin{array}{c}\text { Computer } \\
\text { Software }\end{array}$ \\
\end{tabular} & 2018 / 1 year & 2 & 5 people & $\begin{array}{l}\text { Mobile app / plat- } \\
\text { form } \\
\end{array}$ \\
\hline Main activity & \multicolumn{5}{|c|}{$\begin{array}{l}\text { A mobile app designed for hair care professionals to easily communicate with their custom- } \\
\text { ers: create and save customer data during visits and showcase your work examples to others. }\end{array}$} \\
\hline Start-up B & \begin{tabular}{c|c|}
$\begin{array}{c}\text { Telecommu- } \\
\text { nication }\end{array}$ \\
\end{tabular} & $2011 / 8$ years & 3 & 16 people & $\begin{array}{l}\begin{array}{c}\text { Cloud-enabled plat- } \\
\text { form }\end{array} \\
\end{array}$ \\
\hline Main activity & \multicolumn{5}{|c|}{$\begin{array}{l}\text { Smart, connected, and on-demand communication experiences in nearly any environ- } \\
\text { ment. The goal is to deliver the most natural and pervasive face-to-face communication } \\
\text { experience possible. }\end{array}$} \\
\hline tart-up C & \begin{tabular}{|c|} 
Information \\
Technology \\
and Services
\end{tabular} & 2017 / 2 years & 2 & 18 people & $\begin{array}{l}\text { ID scanning soft- } \\
\quad \text { ware }\end{array}$ \\
\hline Main activity & \multicolumn{5}{|c|}{$\begin{array}{l}\text { Identity verification company, which helps reducing frauds, make business smoother, and } \\
\text { make it more profitable. This company provides the possibility to turn smartphones (iOS } \\
\text { and Android) or computers into a } 24 / 7 \text { ID scanning terminal and facial recognition system } \\
\text { that makes it fast and easy to capture and verify customer identity to meet KYC (Know } \\
\text { Your Customer) and other regulations requirements. }\end{array}$} \\
\hline tart-up D & $\begin{array}{c}\text { E-Marketing } \\
\text { and Advertis- } \\
\text { ing }\end{array}$ & 2018 / 1 year & 1 & 5 people & $\begin{array}{l}\text { Mobile app / plat- } \\
\quad \text { form }\end{array}$ \\
\hline Main activity & \multicolumn{5}{|c|}{$\begin{array}{l}\text { A cloud-based platform for building and managing a customer loyalty program powered } \\
\text { with analysis and communication tools that do not require any additional integrations for } \\
\text { serving a customer. The platform connects all loyalty programs into one network and } \\
\text { gives access to it through a single mobile application. }\end{array}$} \\
\hline tart-up E & $\begin{array}{c}\text { Electri- } \\
\text { cal/Elec- } \\
\text { tronic Manu- } \\
\text { facturing }\end{array}$ & 2016 / 3 years & 1 & 3 people & $\begin{array}{l}\text { Technological in- } \\
\text { vention }\end{array}$ \\
\hline Main activity & \multicolumn{5}{|c|}{$\begin{array}{l}\text { Focusing on delivering a revolutionary electric drive to the global market. The patented X } \\
\text { drive is a Plug \& Play solution for making bikes electric. }\end{array}$} \\
\hline tart-up F & \begin{tabular}{|l|} 
E-learning \\
\end{tabular} & 2013 / 6 years & 2 & 15 people & \begin{tabular}{|l|} 
Platform \\
\end{tabular} \\
\hline Main activity & \multicolumn{5}{|c|}{$\begin{array}{l}\text { Company teaches and connects 10-18-year-old students and senior professionals with ta- } \\
\text { lents from business solutions programming, game development, and 3D modelling areas. }\end{array}$} \\
\hline Start-up G & \begin{tabular}{|c|} 
Computer \\
Software
\end{tabular} & $2009 / 10$ years & 4 & 18 people & $\begin{array}{l}\text { Mobile robotics so- } \\
\text { lutions }\end{array}$ \\
\hline Main activity & \multicolumn{5}{|c|}{$\begin{array}{l}\text { The company provides mobile robotics solutions by developing 3D visual perception and } \\
\text { navigation technology for free-ranging vision-guided robotics applications in various indus- } \\
\text { tries, including manufacturing, material handling, and healthcare. The company is well re- } \\
\text { garded for its precise FDA-compliant robotic solution that targets tumours, designed exclu- } \\
\text { sively for an image-guided radiation therapy product by Elekta, a medical device manufac- } \\
\text { turer listed on NASDAQ OMX NORDIC. The company provides hardware, software, and ser- } \\
\text { vices to enable self-driving vehicle development, deployment, and fleet operation. The com- } \\
\text { pany can convert selected customer vehicle platforms into robotic systems. }\end{array}$} \\
\hline
\end{tabular}

Source: own elaboration based on the analysed start-ups' websites. 


\section{RESULTS AND DISCUSSION}

Case study results showed that integrative behavioural learning is the most commonly used method of organisational learning among Lithuanian technology-based start-ups, while the group that employs behavioural learning is the biggest. Therefore, it can be assumed, that Lithuanian technology-based start-ups are more likely to learn from mistakes, because behavioural learning methods can be specified as "learning from mistakes" instead of applying cognitive or action learning practices.

While analysing the dynamic process used in start-ups' organisational learning, it can be observed that the learning methods are most often interpreted, i.e. start-up teams try to understand the verbal and non-verbal communication of the whole organisation when certain actions are performed. Noteworthy, when the actions of colleagues are already interpreted, they are followed by a fairly frequent integration process, according to which we may assume that Lithuanian technology-based start-ups seek to generate a common and collective understanding of all members of the organisation, implement coordinated actions in start-up activities, and approach institutionalised processes in their activities.

In Lithuanian technology-based start-ups the method of behavioural learning is used the most in their growth and international expansion. This method is interpreted and integrated in organisation activities. As is typical for this learning method, start-ups investigate the responses of their team members and their product/service users to a particular company's routine. Start-up A's founder and CEO states that:

I am using the program myself, I am constantly talking and presenting it to my colleagues, improving together, and the possibilities came from that dialogue. For us, the whole process is constantly dictated by the market. Our wish is to use all the opportunities of the market [its exploitation]. / We talk to our customers, get feedback from them, and according to that feedback fix the app.

The results showed that the start-up teams are learning from their mistakes. This can be seen in Start-up E's example, whose founder reports:

Before the first Kickstarter in 2013, we didn't even suspect that it would be so complicated to have so many new components created, tested, and launched on the market. We didn't really know that. We learned this from this very difficult situation. We fell, we got up, we learned, and we did it again. And after a little while, we've solved those problems.

This type of learning extends the final product/service result due to the required fixes only after the malfunction has been implemented, as it can be seen in the words of Start-up D's co-founder:

Every Wednesday we are doing a team meeting, when every manager presents in what position they are in the process of app development. If any idea comes to our minds, we all discuss how to apply it in the best possible way. We often think in one direction but after a week we say, "No, this is really wrong, we should do it differently." 
Moreover, the routines that arise from behavioural learning are first used within the group and are later transmitted to another group, hence they become common and collective knowledge for the whole organisation. This circumstance appears in Start-up C's founder's words: "Now, we are working very hard for the sales team to communicate with the IT department. Because sales feedback comes from customers, so salespeople should emphasise what the client wants from the IT department and only then do priorities appear."

After analysing the behavioural learning method in start-up activities, we may assume that Lithuanian technology-based start-ups learn from own mistakes. They analyse the reactions of both their team members and external partners. Then, they adapt that information to the results for improvements of start-up product/service. First by interpreting and checking it in smaller work teams and then integrating it across the whole organisation as organisational learning practice.

Lithuanian technology-based start-ups also use the cognitive learning method in their activities to ensure the presence of learning processes rather than respond to the consequences of team members' behaviour. The use of cognitive learning method in start-up activities is very closely related to start-up founders, because they promote the application of this learning process by intuiting it.

According to Start-up D's founder, start-ups use this method by trying to get particular knowledge in the field from persons who are more experienced and capable of providing the necessary knowledge:

Our main manager travelled through all the companies connected with the start-up community. He presented our business model, asked for advice, reflected on our mistakes and advantages. He has a few colleagues working with start-ups, so they also asked for advice from surrounding people on how to make our product better. So, he has tried to get the most knowledge and experience, and learn which problems we can face in the future or now. / We started contacting other start-ups by asking how they solved all these problems. After that, we created a big model of work, a working plan, and we started to do sprints with specific tasks which we should achieve in a certain amount of time; we wanted to do them purely, as one hundred percent functional, and so we gradually arrived at the goal. / We communicated with Invest Lithuania, with all the other start-ups, and with others to get the best possible knowledge and adapt our entire model as best as we can.

Learning from other team members, that have the extraordinary skills in the particular field, was another practice used by founders. According to Start-up A's and Startup F's founders':

[Engineering] education helped a lot and, of course, experience from previous practices. / It all started with the knowledge we already had. In the same field, in the same sector - in the training sector and in the technology sector - but also because at least a few dozen people have always been around in my circle of friends who did it all the time and where I was able to watch and actively do it myself all the same.

Most commonly, purposefully gained knowledge is interpreted by start-up teams in an attempt to absorb the best and most appropriate solutions proposed for their activity, and later integrate the most appropriate information in their processes. Hence, we may 
assume that the cognitive learning method is exploited by start-ups to purposefully transform acquired knowledge into a shared start-up knowledge that improves operational processes and creates competitive advantage.

The institutionalised method of organisational learning is also in use by Lithuanian technology-based start-ups' but less frequently compared to other methods. According to the response of Start-up B's founder, this method is used to follow up on a common team solution with quick actions; to find the best way to improve the product: "Someone has an idea, then we would discuss it together, see it fit or not, and then decide whether to implement it in the system. / We talked and made decisions together, we were a single team. In the form of communication and discussion, ideas were born and implemented."

After the team discussion, as founder of Start-up F states, and after receiving valuable knowledge from outside consultants, according to Start-up A's founder:

Product development opportunities are inevitable. A simple form is the conversation between the founder and the staff going on every day. And this is about these things. / An accelerator helps with everything. For me it is the first time, everything is new but very interesting. We receive training in different fields: finance, marketing, sales. I haven't heard so much information about my idea yet. People from the side look into our idea, analyse it, and that helps me and the team a lot.

Prior to start-ups' coordinated actions triggered by the action learning method, the information received is first embedded in the start-up team and later, after verification, integrated into the organisation as a whole.

\section{CONCLUSIONS}

The study defined start-ups development model, growth stages, and aspects of organisational learning: its methods (behavioural, cognitive, action), dynamic processes (intuiting, interpreting, integrating, and institutionalizing), and the benefits of its application, such as enhancing competitive advantage, constant market monitoring, promoting a common organisational culture, and ensuring inter-knowledge sharing. However, as prior literature emphasises, there are very limited studies that try to understand the outcomes of learning as a social phenomenon (Nogueira, 2019), entrepreneurial learning as part of organisational learning, and what impact they have on start-up survival and development (Krishna, 2018).

The results revealed that Lithuanian start-ups established in various technology sectors acknowledge the benefits of start-up learning. Lithuanian technology-based startups use three organisational learning methods: an error-learning approach, learning both from own mistakes and external mistakes, experienced and deliberately assured learning methods, start-up teams learn from their own entrepreneur or from other external individuals who can provide the required knowledge. Then fast needed decisions are made. Learning mentioned in start-up activities is accepted intuitively, later interpreted an integrated. However, Lithuanian technology-based start-ups have not yet institutionalised the benefits of organisational learning. The following managerial implications stem from the results of our research.

Seed stage. This can be overcome with the use of organisational learning behavioural method when the feedback from potential clients has to be discussed together in the team and further product adjustment processes are overcome by correcting the mistakes that 
have been made so far in the product. As business knowledge deficiencies raise further challenges at this stage, we advise start-up developers to participate regularly in start-ups ecosystem before beginning the start-up and during the first development phases, which can provide primary knowledge needed for business development; especially when it comes to acquiring certain required information with the use of cognitive learning method. Moreover, it is essential to develop social skills and use social networks, which contributes to the development of the social capital of a start-up (Brockman, 2013).

Start-up stage. This challenge can be softened by monitoring competitors on the market, analysing their product/service, and finding gaps that would be relevant to consumers, thus overcoming the possible practices of action learning method. In order to solve the challenges of organisational management as smoothly as possible, we advise consulting with external partners (cognitive learning) or overcoming the behavioural method of organisational learning by learning from mistakes. According to Tam and Gray (2016), managers of an enterprise should take lead in group learning activities and create a shared learning culture in the workplace.

Growth/expansion stage. It is in such situations that the action learning process is used most often because of a quick reaction and problem solving at a given moment. We recommend that all organisational learning methods at this stage be institutionalised throughout the start-up organisation. Thus, this study suggests that start-up founder/cofounders should align and promote $\mathrm{OL}$ with growth stages of start-ups to maximise employee learning effectiveness, which will lead to versatile growth.

Certainly, this research has its limitations. Only start-ups from Lithuanian market were analysed, so the results cannot be applied to start-ups from other markets. This study could be a foundation for future comparison. Moreover, future research may conduct a deeper analysis of the challenges and organisational learning practices of start-ups. Thus, we recommend focusing more on how to solve the challenges through the use of organisational learning benefits. Try to find a closer relationship between the challenges faced by start-ups and organisational learning practices. More extensive researches (e.g. quantitative) can be conducting for covering different sectors. Another direction could be empirical studies that would compare start-ups in countries in transition (e.g. CEE countries), because they lack entrepreneurial business ecosystems and an environment favourable to investments, start-up growth, and effective learning practices.

\section{REFERENCES}

Aldrich, H.E., \& Yang, T. (2012). Lost in translation: Cultural codes are not blueprints. Strategic Entrepreneurship Journal, 6(1), 1-17.

Alvarez, S.A., \& Busenitz, L.W. (2001). The entrepreneurship of resource-based theory. Journal of Management, 27(6), 755-775.

Baggen, Y., Lans, T., Biemans, H.J.A., Kampen J., \& Mulder, M. (2016). Fostering Entrepreneurial Learning On-the-Job: evidence from innovative small and medium-sized companies in Europe. European Journal of Education, 51(2), 193-209.

Bailetti, A.J. (2012). What technology startups must get right to globalize early and rapidly. Technology Innovation Management Review, 5-16.

Blank, S., \& Dorf, B. (2012). The startup owner's manual: The step-by-step guide for building a great company. BookBaby. 
Bosch, J., Olsson, H.H., Björk, J., \& Ljungblad, J. (2013). The early stage software startup development model: a framework for operationalizing lean principles in software startups. In International Conference on Lean Enterprise Software and Systems (pp. 1-15). Berlin, Heidelberg: Springer.

Brockman, B.K. (2013). The evolution of organizational learning in new venture development. Journal of Small Business and Entrepreneurship, 26(3), 261-275.

Bürgel, O., Fier, A., Licht, G., \& Murray, G. (2004). The Internationalisation of Young High-Tech Firms. In ZEW Economic Studies 22. Verlag, Berlin, Heidelberg: Springer.

Cantamessa, M., Gatteschi, V., Perboli, G., \& Rosano, M. (2018). Startups' roads to failure. Sustainability, 10(7), 2346.

Chandler, G.N., \& Lyon, D.W. (2009). Involvement in Knowledge-Acquisition Activities by Venture Team Members and Venture Performance. Entrepreneurship Theory and Practice, 33(3), 571-592.

Chen, Y.H., Lin, T.P., \& Yen, D.C. (2014). How to facilitate inter-organizational knowledge sharing: The impact of trust. Information and Management, 51(5), 568-578.

Chung, P., \& Bowie, R. (2017). Dhl: From Startup to Global Upstart. Boston: DEG Press.

Cosenz, F., \& Noto, G. (2018). Fostering entrepreneurial learning processes through Dynamic Start-up business model simulators. The International Journal of Management Education, 16(3), 468-482.

Crossan, M.M., Lane, H.W., \& White, R.E. (1999). An organizational learning framework: From intuition to institution. Academy of Management Review, 24(3), 522-537.

Dutta, D.K., \& Crossan, M.M. (2005). The nature of entrepreneurial opportunities: understanding the process using the $4 \mathrm{I}$ organizational learning framework. Entrepreneurship Theory and Practice, 29(4), 425-449.

Eisenhardt, K.M. (1989). Building Theories from Case Study Research. Academy of Management Review, 14(4), 532-50.

Eisenhardt, K.M., \& Graebner, M.E. (2007). Theory building from cases: Opportunities and challenges. Academy of Management Journal, 50(1), 25-32.

Ghezzi, A. (2019). Digital startups and the adoption and implementation of Lean Startup Approaches: Effectuation, Bricolage and Opportunity Creation in practice. Technological Forecasting and Social Change, 146, 945-960.

Henry, P. (2017). Why Some Startups Succeed (and Why Most Fail). Retrieved from https://www.entrepreneur.com/article/288769 on October 7, 2019.

InvestLithuania (2019). Why choose Lithuania. Retrieved from https://investlithuania.com/why-lithuania/ on October 7, 2019.

Jones, O., Macpherson, A., \& Jayawarna, D. (2014). Resourcing the start-up business: Creating dynamic entrepreneurial learning capabilities. Routledge.

Jones, O., \& Macpherson, A. (2006). Inter-Organizational Learning and Strategic Renewal in SMEs. Extending the 4I Framework. Long Range Planning, 39, 155-175.

Karataş-Özkan, M. (2011). Understanding relational qualities of entrepreneurial learning: towards a multi-layered approach. Entrepreneurship and Regional Development, 23(9-10), 877-906.

Koryak, O., Mole, K.F., Lockett, A., Hayton, J.C., Ucbasaran, D., \& Hodgkinson, G.P. (2015). Entrepreneurial leadership, capabilities and firm growth. International Small Business Journal, 33(1), 89-105.

Krishna, H.S. (2018). Entrepreneurial Learning and Indian Tech Startup Survival: An Empirical Investigation. Asian Journal of Innovation and Policy, 7(1), 55-78.

Lichtenstein, B.M.B., \& Brush, C.G. (2001). How do "resource bundles" develop and change in new ventures? A dynamic model and longitudinal exploration. Entrepreneurship Theory and Practice, 25(3), 37-58. 
Lewis, V.L., \& Churchill, N.C. (1983). The five stages of small business growth. Harvard Business Review, 61(3), 30-50.

Lumpkin, G., \& Lichtenstein, B. (2005). The Role of Organizational Learning in the OpportunityRecognition Process. Entrepreneurship Theory and Practice, 29(4), 451-472.

MaRS (2009a). Concept stage of company development: Funding, investors, risks, and expectations. Retrieved from https://www.marsdd.com/mars-library/concept-stage-of-company-development-funding-investors-risks-and-expectations/ on October 10, 2019.

MaRS (2009b). Startup phase of company development: Funding, investors, risks and expectations. Retrieved from https://www.marsdd.com/mars-library/startup-phase-of-company-development-funding-investors-risks-and-expectations/ on October 10, 2019.

MaRS (2009c). Venture capital: Financing a startup in the growth stage of company development. Retrieved from https://www.marsdd.com/mars-library/venture-capital-financing-a-startup-inthe-later-stages-of-growth/ on October 10, 2019.

MaRS (2009d). Venture capital: Financing a startup in the later stage of company development. Retrieved from https://www.marsdd.com/mars-library/venture-capital-financing-a-startup-inthe-later-stage-of-company-development/ on October 10, 2019.

Motoyama, Y., \& Knowlton, K. (2017). Examining the connections within the startup ecosystem: A case study of St. Louis. Entrepreneurship Research Journal, 7(1), 2194-6175.

Mueller, S., Volery, T., \& von Siemens, B. (2012). What Do Entrepreneurs Actually Do? An Observational Study of Entrepreneurs' Everyday Behavior in the Start-Up and Growth Stages. Entrepreneurship Theory and Practice, 36(5), 995-1017.

Nogueira, T.F. (2019). Entrepreneurial learning: what do we mean by it?. The Learning Organization, 26(6), 560-573.

Paschen, J. (2017). Choose wisely: Crowdfunding through the stages of the startup life cycle. Business Horizons, 60(2), 179-188.

Pomerol, J.C. (2018). Business uncertainty, corporate decision and startups. Journal of Decision Systems, 27(1), 32-37.

Salamzadeh, A., \& Kawamorita Kesim, H. (2017). The enterprising communities and startup ecosystem in Iran. Journal of Enterprising Communities: People and Places in the Global Economy, 11(4), 456-479.

Sekliuckiene, J., Vaitkiene, R., \& Vainauskiene, V. (2018). Organisational learning in startup development and international growth. Entrepreneurial Business and Economics Review, 125-144.

Silverman, D. (Ed.). (2016). Qualitative research. London: Sage.

Soetanto, D. (2017). Networks and entrepreneurial learning: coping with difficulties. International Journal of Entrepreneurial Behavior and Research, 23(3), 547-565.

Sofaer, S. (2002). Qualitative research methods. International Journal for Quality in Health Care, 14(4), 329-336.

StartupLithuania (2019). Ecosystem. Retrieved from https://www.startuplithuania.com/ecosystem/ on December 8, 2019.

Swanson, J.A., \& Baird, M.L. (2003). Engineering your start-up: A guide for the high-tech entrepreneur (2nd ed.). Belmont, CA: Professional Publications.

Sweetwood, M. (2018). Infographic: The 20 Most Common Reasons Startups Fail and How to Avoid Them. Retrieved from https://www.entrepreneur.com/article/307724 on February 19, 2019. 
Tam, S., \& Gray, D.E. (2016). Organisational learning and the organisational life cycle: the differrential aspects of an integrated relationship in SMEs. European Journal of Training and Development, 40(1), 2-20.

Tech, R.P. (2014). Crowdfunding Hardware Startups in Germany. In Proceedings of Twenty Second European Conference on Information Systems. Retrieved from https://aisel.aisnet.org/ecis2014/proceedings/track17/4/ on February 11, 2019.

Van Osnabrugge, M., \& Robinson, R.J. (2000). Angel Investing: Matching Start-up Funds with Start-up Companies - The Guide for Entrepreneurs and Individual Investors (1st ed.). John Wiley \& Sons.

Wang, X., Edison, H., Bajwa, S.S., Giardino, C., \& Abrahamsson, P. (2016). Key challenges in software startups across life cycle stages. In International Conference on Agile Software Development (pp. 169-182). Cham: Springer.

Yin, R.K. (2003). Designing case studies. Qualitative Research Methods, 359-386. 


\section{Authors}

The contribution share of authors is equal and amounted to $50 \%$ each of them.

\section{Viktorija Baltrunaite}

Bachelor of Finance and Marketing (Kaunas University of Technology, Lithuania); Master in International Business (Kaunas University of Technology, Lithuania). Her research interests include international entrepreneurship and innovations, organisational learning.

Correspondence to: Viktorija Baltrunaite, Kaunas University of Technology, School of Economics and Business, Gedimino st. 50-415, Kaunas, Lithuania, e-mail: viktorija.baltrunaite@ktu.It

\section{Jurgita Sekliuckiene}

Professor of International Business and head of International Entrepreneurship research cluster at the Kaunas University of Technology. She received her PhD in Management and Business Administration from the Kaunas University of Technology. Her research interests are in the area of internationalisation, international entrepreneurship and innovation, networks, and export strategies, with a special interest in transition market INVs and multinationals. She is the author and co-author of conference contributions, over 40 peer-reviewed publications, and several books and monograph chapters in the field of international business, strategic management, and emerging markets. She is a member of the Academy of International Business (AIB) and European International Business Academy (EIBA).

Correspondence to: Prof. dr. Jurgita Sekliuckiene, Kaunas University of Technology, Schoolof Economics and Business, Gedimino st. 50-415, Kaunas, Lithuania, e-mail: jurgita.sekliuckiene@ktu.It ORCID (1) http://orcid.org/0000-0001-8899-3112

\section{Acknowledgements and Financial Disclosure}

This research was supported by the Research, Development, and Innovation Fund of Kaunas University of Technology (GLOBAL STARTUP Project No. PP32/1810).

\section{Copyright and License}

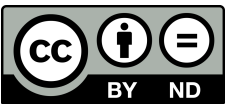

This article is published under the terms of the Creative Commons

Attribution - NoDerivs (CC BY-ND 4.0) License

http://creativecommons.org/licenses/by-nd/4.0/

Published by the Centre for Strategic and International Entrepreneurship - Krakow, Poland 
